\title{
A NEW SPECIES OF THE GENUS Plesiocoelus van Achterberg (Hymenoptera: Braconidae: Agathidinae) FROM VIETNAM
}

\author{
Khuat Dang Long ${ }^{1 *}$, Cornelis van Achterberg ${ }^{2}$ \\ ${ }^{1}$ Institute of Ecology \& Biological Resources, VAST, Vietnam \\ ${ }^{2}$ Department of Terrestrial Zoology, NCB Naturalis, Postbus 9517, 2300 RA Leiden,
} The Netherlands

\begin{abstract}
Plesiocoelus van Achterberg is a rare genus of the subfamily Agathidinae (Braconidae). The genus was established by van Achterberg in 1990 with one Neotropical species included, Plesiocoelus bassiformis van Achterberg, 1990. Based on specimens deposited at the Institute of Ecology \& Biological Resources (IEBR) and Vietnam National Museum of Nature (VNMN), the genus Plesiocoelus van Achterberg is newly recorded from Vietnam with a new species, Plesiocoelus vietnamicus Long \& van Achterberg, sp. n. described and illustrated in this paper. Differences between the new species and P. bassiformis van Achterberg, are given.
\end{abstract}

Keywords: Braconidae, Agathidinae, Plesiocoelus, new record, new species, Neotropical, Oriental, Vietnam.

Citation: Khuat Dang Long, Achterberg C. van, 2016. A new species the genus Plesiocoelus van Achterberg (Hymenoptera: Braconidae: Agathidinae) from Vietnam. Tap chi Sinh hoc, 38(3): 304-309. DOI: 10.15625/0866-7160/v38n3.8722.

*Corresponding author: khuatdanglong@gmail.com.

\section{INTRODUCTION}

Agathidinae is a moderately large subfamily of Braconidae and has a worldwide distribution; members of this subfamily are found in most terrestrial habitats. In the recent revision of the Agathidinae from Vietnam by van Achterberg \& Long (2010) [5], seventeen genera of Agathidinae from Vietnam were revised. This work gave an overview of the diversity of Agathidinae of Vietnam and provided keys to genera and all known agathidine species from Vietnam. In this work, five genera, viz. Hypsostypos Baltazar, 1963; Cremnoptoides van Achterberg \& Chen, 2004; Oreba Cameron, 1900; Aneurobracon Brues, 1930 and Falcilagathis van Achterberg \& Chen, 2004, were supposed to be occur in Vietnam, but unfortunately not found so far. Up to now, the genus Plesiocoelus named by van Achterberg (1990) [2] has one described species, $P$. bassiformis van Achterberg from the Neotropical region (Colombia, Ecuador and Honduras), and this paper deals with a new record for Vietnam and the description of one new species, Plesiocoelus vietnamicus Long \& van Achterberg, sp. n..

\section{MATERIALS AND METHODS}

Two following collections of the braconid wasps from Vietnam used for this paper are at the Institute of Ecology \& Biological Resources (IEBR) and Vietnam National Museum of Nature (VNMN) at Hanoi. All specimens are assembled during numerous expeditions in Vietnam.

Terminology used in this paper follows van Achterberg (1993) [3], and sculpture terms are based on Harris (1979) [10]. For identification of the subfamily, see van Achterberg (1993, 1997) [3, 4]; for the subdivision of the subfamily see van Achterberg (1993) [3]; for a key to the genera see van Achterberg \& Long (2010) [5], Sharkey et al. (2009) [14]; for additional references and data, see $\mathrm{Yu}$ et al. (2012) [17]. The photographs were made by the first author with a Canon G15 camera attached to an Olympus ${ }^{\circledR}$ SZ61 binocular microscope at IEBR and and processed with Adobe Photoshop CS5 to adjust the size and background.

The following abbreviations are used: $\mathrm{OD}=$ diameter of posterior ocellus; $\mathrm{OOL}=$ ocular-ocellar line; $\mathrm{POL}=$ postocellar line; 
$\mathrm{S}=$ south; $\mathrm{MT}=$ Malaise trap; $\mathrm{NP}=$ National Park. 'Aga.+number' is code number indexing for specimens of the Agathidinae in the collection; VAST stands for Vietnam Academy of Science and Technology. The scale-lines of the plates indicate $\mathrm{mm}$.

\section{RESULTS AND DISCUSSION}

\section{Taxonomy}

\section{Plesiocoelus van Achterberg, 1990}

Plesiocoelus bassiformis van Achterberg, 1990: 44. Type-species Plesiocoelus bassiformis van Achterberg, 1990.

\section{Diagnosisof genus}

Head somewhat elongate and with temple distinctly concave behind malar space (fig. 2); pedicellus medium-sized; frons distinctly concave behind and near inner side of antennal sockets (fig. 2), and with median crest, continuing on dorsal third of face; prepectal carina complete and low on mesopleuron (fig. 4); precoxal sulcus present posteriorly, and absent anteriorly (fig. 4); mesopleuron largely smooth; notauli narrow, complete, united in front of scutellar sulcus (fig. 9); scutellum steep posteriorly, without semi-circular depression posteriorly, and carinate apically (fig. 9); propodeum irregular reticulate-rugose, with median carina short, indistinct and without medial area (fig. 9); propodeal spiracle mediumsized and close to anterior margin of propodeum (see fig. 8 in van Achterberg, 1990); vein 1-R1 of fore wing distinctly longer than pterostigma (fig. 6); veins CU1, 2-SR+M, 2-SR and m-cu of fore wing sclerotized; vein $r$ of fore wing emitted near basal 0.4 of pterostigma (fig. 6); vein 2-CU of hind wing present as weak fold of membrane only; length of fore tibial spur 0.4 times forebasitarsus (see fig. 3 in van Achterberg, 1990); hind tarsus distinctly depressed; length of inner hind spur 0.5-0.6 times basitarsus; hind trochantellus about as long as hind trochanter (see fig. 10 van Achterberg, 1990); hind tarsal claws with lobe (fig. 11); apex of hind tibia with pegs (fig. 12); length of first metasomal tergite 1.8-2.0 times its apical width; second tergite with sharp lateral crease (fig. 3, see fig. 10 van Achterberg, 1990); second metasomal suture indistinct (fig. 3); length of ovipositor sheath $0.5-0.8$ times fore wing; hypopygium of female medium-sized and apically truncate (fig. 1).

Notes: Plesiocoelus van Achterberg, 1990 belongs to subtribe Mesocoelina [2] and this genus differs from Aneurobracon Brues, 1930 by having the enlarged propodeal spiracles; the less elongate propodeum; the concave temples; the lack of scutellar depression posteriorly; the tarsal claws with lobe; the pedicellus not enlarged; the depression near inner side of antennal sockets present and the short hind trochantellus. Plesiocoelus differs from Mesocoelus Schulz, 1911 by head more or less elongate; prepectal carina and notauli present (that completely absent in Mesocoelus); hind tibia with row of pegs (fig. 12); tarsal claws with lobe (without in Mesocoelus); veins r, 2SR, 1-CU1 and 2-CU1 of fore wing sclerotized.

\section{Biology. Unknown.}

Distribution. Neotropical; Oriental.

\section{Plesiocoelus vietnamicus Long \& van Achterberg, sp. n. (Figs 1-12)}

Material. Holotype, female, (VNMN), 'Aga.532', S. Vietnam: Dong Nai, Cat Tien NP, MT, 1-8.iv.2009, M. P. Quy, N. T. Manh.

Diagnosis. Female, small wasp, length of body slightly shorter than antenna; fore wing distinctly shorter than body (fig. 1); outer side of middle leg with row of pegs (figs. 8, 10); hind tibia with row of pegs (fig. 12); hind tarsal claw with large lobe (fig. 11); hind tibial spurs 0.35 and 0.5 times as long as hind basitarsus; wings faintly pigmented; fore wing with veins $r$, 2-SR, 1-CU1 and 2-CU1 sclerotized (fig. 6); vein $1-C U 1$ of fore wing very short, much shorter (0.1 times) than vein 2-CU1; vein M-CU of hind wing slightly shorter than 1-M; propodeum with short basal median carina, reticulate-rugose (figs. 5, 9); propodeal spiracle round, medium-sized, close to the upper corner of propodeum; first metasomal tergite sparsely striate; suture between second and third tergites indistinct; the surface of second tergite superficially coriaceous; third-sixth tergites polished, smooth (fig. 3); ovipositor sheath 0.5 
times as long as body length.

Notes. The new species differs from Plesiocoelus bassiformis van Achterberg by having: a)- in dorsal view length of eye 3.7 times as long as temple (2.8 times in $P$. bassiformis); b)- Outer side of middle tibia with row of pegs (fig. 9); c)- First metasomal tergite sparsely striate (largely shiny and punctate in $P$. bassiformis) and d)- Second metasomal tergite shiny, coriaceous (superficially granulate in P. bassiformis).

Description. Holotype, female, body length $3.2 \mathrm{~mm}$; fore wing length $2.8 \mathrm{~mm}$; antenna 3.3 $\mathrm{mm}$; ovipositor sheath $1.51 \mathrm{~mm}$ (fig. 1).

Head. Antenna with 32 segments; middle segments 3.0 times longer than wide $(6: 2)$; third antennal segment 1.3 times fourth (8:6); length of third, fourth and penultimate segments 4.0, 3.0 and 1.7 times their width, respectively; length of maxillary palp 0.8 times height of head; width of face as long as length of face and clypeus combined; malar space 1.7 times as long as mandible width (5:3); in dorsal view length of eye 3.7 times as long as temple (11:3); in lateral view, width of eye 3.3 times as long as temple (10:3); ocelli medium, POL:OD:OOL
$=3: 2.5: 5$; distance between anterior ocellus and hind ocelli 0.5 times as long as OOL (fig. 2); face shiny, sparsely and finely punctate; frons, vertex and temple smooth.

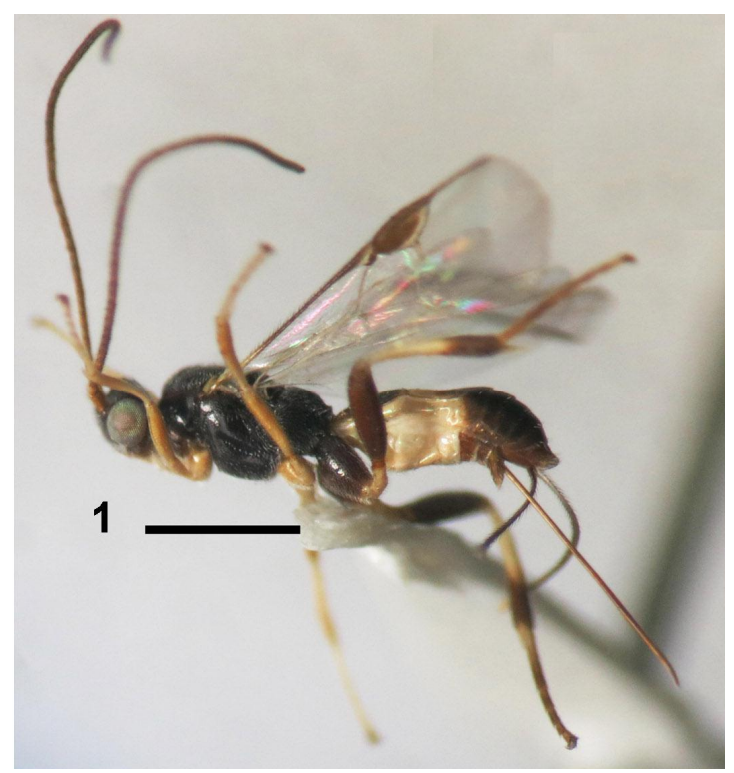

Figure 1. Plesiocoelus vietnamicus Long \& van Achterberg, sp. n., holotype, female, habitus, lateral aspect.

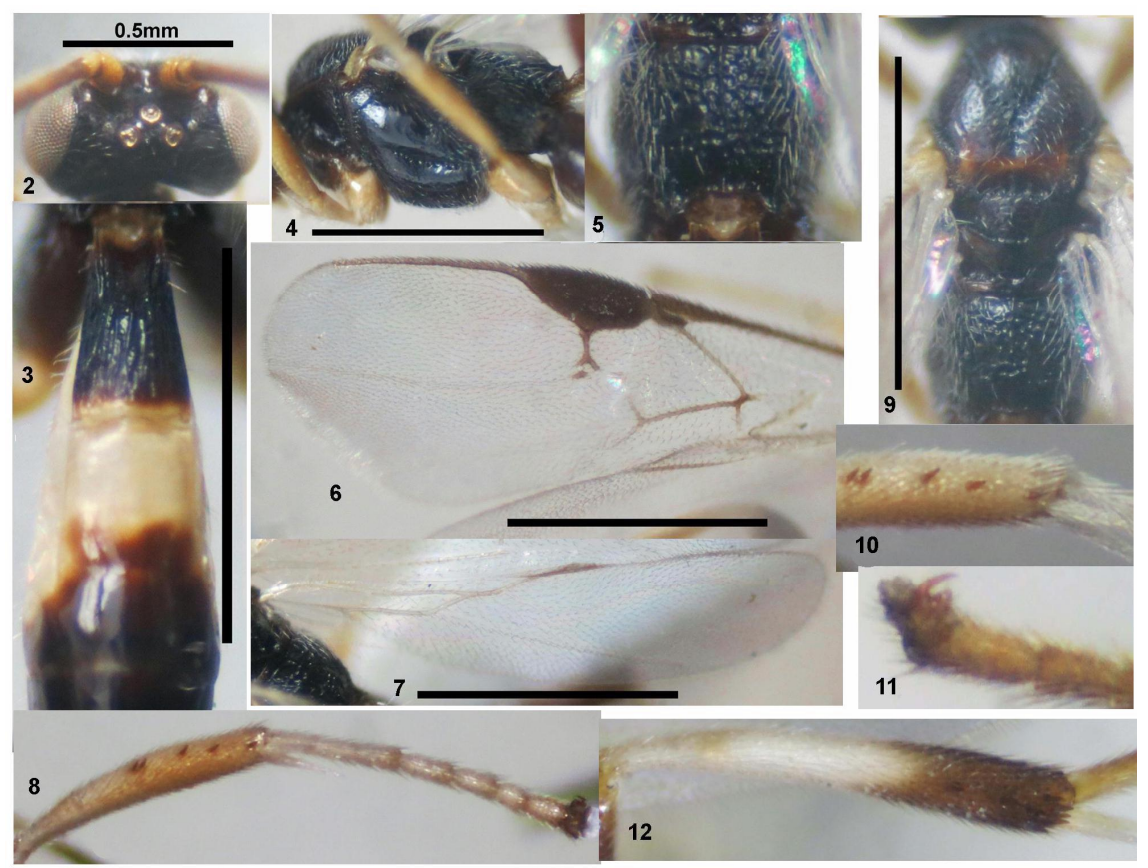

2. Head, dorsal aspect;

3. First - fourth metasomal tergites; 4. Mesopleuron;

5. Propodeum;

6. Fore wing;

7. Hind wing;

8. Outer side of middle leg; 9. Mesosoma; 10. Row of pegs on outer side of middle tibia; 11. Hind tarsal claw;

12. Outer side of hind tibia.

Figures 2-12. Plesiocoelus vietnamicus Long \& van Achterberg, sp. n., holotype, female 
Mesosoma. Length of mesosoma 1.6 times as long as high (49:30); propleuron crenulate anteriorly, smooth posteriorly (fig. 4); median lobe of mesoscutum sparsely punctate, lateral lobes of mesoscutum superficially punctate, smooth apically; notauli deep, crenulated (fig. 4); precoxal sulcus wide, rather long, punctate (fig. 4); mesopleuron largely smooth; metapleuron punctate; scutellar sulcus deep, 0.6 times as long as scutellum (3:5) with two strong median carinae and two lateral short carinae (fig. 9); scutellum carinate apically, nearly smooth (fig. 9); propodeum with short basal median carina, reticulate-rugose (figs 5, 9); propodeal spiracle round, medium-sized, close to the upper corner of propodeum.

Wings. Fore wing: length of pterostigma 1.6 times as long as wide (22:14) and 5.5 times vein $\mathrm{r}$; length of pterostigma 0.8 times as long as vein 1-R1 (22: 28); vein $\mathrm{r}$ arising just before middle of pterostigma (fig. 6); vein cu-a vertical; vein 1-CU1 0.1 times as long as 2-CU1 (1.5:15). Hind wing: vein $\mathrm{M}+\mathrm{CU} 0.92$ times vein 1-M (12:13) (fig. 7).

Legs. Apically inner and dorsal side of hind coxa finely granulate, outer side of hind coxa finely punctate; femur:tibia:basitarsus: tarsus $=30: 39: 21$; length of hind femur, tibia and basitarsus 3.75, 6.5 and 10.5 times as long as their width, respectively; outer side of apical half of middle tibia with row of five pegs (figs 8,10 ); middle tibial inner spur 0.61 times middle basitarsus (8:13); hind tibial spurs 0.35 and 0.5 times as long as basitarsus; hind basitarsus as long as second-fifth tarsus; hind tarsal claw simple with large lobe (fig. 11).

Metasoma. First tergite 1.8 times as long as apical width (20:11) (fig. 3); medial length of second tergite 1.4 times than third (14:10); tergites 1 with sparse striae, smooth apically (fig. 3); second tergite shiny, finely coriaceous; third-sixth tergites polished, smooth; second suture faint (fig. 3); ovipositor sheath 0.54 times fore wing (62:115); ovipositor straight, slightly curved at apex (fig. 1).

Colour. Brown; head and mesosoma darkish brown; palpi ivory to white; scape and pedicel light yellow; antennal flagellum yellowish brown; fore and middle legs light yellow; hind coxa and fermur light brown; trochanter and trochantellus yellow; basal two third of hind tibia whitish yellow; apical one third of hind tibia yellowish brown; hind tibial spurs yellow; hind tarsus yellowish brown; fore and hind wings faintly pigmented (figs 6, 7); wings yellow; fore wing with pterostigma, veins $\mathrm{C}+\mathrm{SC}+\mathrm{R}, \mathrm{r}, 2-\mathrm{SR}$ and 1-R1 light brown; first metasomal tergite dark brown, ivory apically; second tergite ivory but yellow apically; firstsecond sternites ivory; third-six metasomal tergites brown; ovipositor sheath brown.

Male. Unknown.

Distribution. S. Vietnam (Dong Nai).

Biology. Unknown.

Etymology. The name of the species originates from the name of the country, where the holotype was collected.

Acknowledgements: This paper has been produced with the fund of the Vietnam National Foundation for Science and Technology Development (NAFOSTED). Thanks are due to Ass. Prof. Mai Phu Quy and Dr Nguyen Thanh Manh (IEBR) for providing specimens.

\section{REFERENCES}

1. Achterberg C. van, 1988. Revision of the subfamily Blacinae Foerster (Hymenoptera, Braconidae). Zoologische Verhandelingen Leiden, 249: 1-324.

2. Achterberg C. van, 1990. Revision of the subtribe Mesocoelina Viereck (Hymenoptera: Braconidae). Zoologische Mededelingen Leiden, 76: 31-57.

3. Achterberg C. van, 1993. Illustrated key to the subfamilies of the Braconidae (Hymenoptera: Ichneumonoidea). Zoologische Verhandelingen Leiden, 283: 1-189.

4. Achterberg C. van, 1997 Braconidae. An illustrated key to all subfamilies. ETI World Biodiversity Database CD-ROM Series Amsterdam.

5. Achterberg C. van, Long K. D., 2010. Revision of the Agathidinae (Hymenoptera, 
Braconidae) of Vietnam, with the description of forty-two new species and three new genera. ZooKeys, 54: 1-184. doi: 10.3897/zookeys.54.475.

6. Bhat S., Gupta V. K., 1977. The subfamily Agathidinae (Hymenoptera, Braconidae) Ichneumonologia Orientalis, Oriental Insects Mon., 6: 1-353.

7. Chen J. H., Yang J. Q., 2006. Hymenoptera, Braconidae (IV), Agathidinae. Fauna Sinica Insecta, 46: 1-301.

8. Chou L. Y., Sharkey M. J., 1989. The Braconidae (Hymenoptera) of Taiwan. 1. Agathidinae. Journal of the Taiwan Museum, 42: 147-223.

9. Granger C., 1949. Braconides de Madagascar. Memoires de l'Institut Scientifique de Madagascar. (A)2: 1-428.

10. Harris R. A., 1979. A glossary of surface sculpturing. Occasional Papers in Entomology, California Department of Food and Agriculture, 28: 1-33.

11. Khuat Dang Long, Achtererg C. van, 2014. An additional list with new records of braconid wasps of the family braconidae (Hymenoptera) from Vietnam. Tap chi Sinh hoc, 36(4): 397-415. DOI: 10.15625/0866$7160 / \mathrm{v} 36 \mathrm{n} 4.5979$.

12. Khuat Dang Long, Belokobylskij S. A.,
2003. A preliminary list of the Braconidae (Hymenoptera) of Vietnam. Russian Entomological Journal, 12(4): 385-398.

13. Sharkey M. J., 1996. The Agathidinae (Hymenoptera: Braconidae) of Japan. Bulletin of the National Institute of AgroEnvironmental Sciences 13: 1-100.

14. Sharkey M. J., Clutts S. A., 2011. A revision of Thai Agathidinae (Hymenoptera: Braconidae), with descriptions of six new species. Journal of Hymenoptera Research 22: 69-132. doi: 10.3897/jhr.22.1299.

15. Sharkey M. J., Laurenne N. M., Sharanowski B., Quicke D. L. J., Murray D., 2006. Revision of the Agathidinae (Hymenoptera: Braconidae) with comparisons of static and dynamic alignments. Cladistics, 22(6): 546-567.

16. Sharkey M. J., Yu D. S., van Noort S., Seltmann K., Penev L., 2009. Revision of the Oriental genera of Agathidinae (Hymenoptera, Braconidae) with an emphasis on Thailand including interactive keys to genera published in three different formats. ZooKeys, 21: 19-54. doi: 10.3897/zookeys.21.271.

17. Yu D. S. K., Achterberg C. van, Horstmann K., 2012.Taxapad 2012, Ichneumonoidea 2011. Ottawa, Ontario, Canada. Database on flash-drive. www.taxapad.com. 


\title{
GHI NHẬN MỚI GIỐNG Plesiocoelus van Achterberg (Hymenoptera: Braconidae: Agathidinae) VÀ MÔ TẢ MộT LOÀI MỚI TỬ KHU Hệ CỦA VIẸT NAM
}

\author{
Khuất Đăng Long ${ }^{1}$, Cornelis van Achterberg ${ }^{2}$ \\ ${ }^{1}$ Viện Sinh thái và Tài nguyên Sinh vật, Viện Hàn lâm KH \& CN Việt Nam \\ ${ }^{2}$ Department of Terrestrial Zoology, NCB Naturalis, Postbus 9517, 2300 RA Leiden, \\ The Netherlands
}

TÓM TẮT

Plesiocoelus van Achterberg, 1990 là một giống hiếm gặp trong phân họ Agathidinae thuộc họ ong ký sinh Braconidae. Giống Plesiocoelus được van Achterberg xác lập năm 1990 với một loài, Plesiocoelus bassiformis van Achterberg, 1990, được mô tả từ khu hệ Nam Mỹ (Colombia, Ecuador và Honduras). Dựa trên bộ sưu tập mẫu ong ký sinh hiện có tại Viện Sinh thái và Tài nguyên sinh vật và Bảo tàng Thiên nhiên Việt Nam, bài báo ghi nhận mới giống Plesiocoelus van Achterberg, 1990 và mô tả một loài mới cho khoa học, Plesiocoelus vietnamicus Long \& van Achterberg, sp. n., từ khu hệ ong ký sinh Braconidae của Việt Nam. Đặc điểm hình thái của loài này được minh họa bằng ảnh màu đồng thời cũng chỉ ra một số đặc điểm hình thái so sánh với loài Plesiocoelus bassiformis van Achterberg, từ vùng Nam Mỹ.

Keywords: Ghi nhận mới, loài mới, ong ký sinh, Nam Mỹ, Đông Phương, Việt Nam.

Received 25 August 2016, accepted 20 September 2016 